\title{
Induction of Excessive B Cell Proliferation and Differentiation by an In Vitro Stimulus in Culture in Human Systemic Lupus Erythematosus
}

\author{
Noboru Suzuki and Tsuyoshi Sakane \\ Third Division, Department of Internal Medicine, Shimane Medical University, Izumo, Shimane 693, Japan
}

\begin{abstract}
B cell hyperactivity present in the body in patients with systemic lupus erythematosus (SLE) can be detectable via almost any measure of $B$ cell function. Nonetheless, the basis for the $B$ cell hyperactivity is difficult to study in vitro. In this study, we have obtained the resting $B$ cells from patients with entirely inactive SLE by collecting them sedimenting in a high density fraction on a Percoll density gradient. These resting SLE B cells proliferated in vitro at a higher rate than normal $B$ cells when exposed to Staphylococcus aureus Cowan I (SAC). In addition, significant proliferation was observed earlier in the course of culture in SLE patients than in normal controls. Moreover, the SLE resting B cells, once triggered by SAC produced abnormally high numbers of immunoglobulin-secreting cells in response to $\mathbf{T}$ cell-derived soluble factors.

There was less frequency of circulating Leu $1^{+} B$ cells in the SLE patients than in normal controls. Moreover, not only Leu $1^{+} B$ cells but also Leu $1^{-}$B cells of SLE patients were more responsive to $\mathrm{SAC}$ than those of normal controls. The results indicate that the $B$ cell hyperactivity in human SLE can be induced by in vitro stimuli, and may not be limited to the Leu $1^{+} B$ cell subset.
\end{abstract}

\section{Introduction}

Systemic lupus erythematosus (SLE) is characterized by B cell hyperactivity and the production of a variety of autoantibodies. The B cell hyperactivity associated with SLE is actually detectable via almost any measure of B cell function: peripheral blood B cells from patients with SLE have significantly greater proliferation than did control B cells $(1,2)$; patients with SLE have markedly increased numbers of spontaneous immunoglobulin (Ig)-secreting cells in their blood as determined by reverse hemolytic plaque-forming cell (PFC) ${ }^{1}$ assay (1, 3-7); SLE patients have increased numbers of B cell colonies generated by peripheral blood non-T cells $(2,8)$; and in-

A preliminary report of this work was presented at the 72nd Annual Meeting, Federation of American Societies for Experimental Biology, 5 May 1988.

Address reprint requests to Dr. Sakane, Third Division, Department of Internal Medicine, Shimane Medical University, Izumo, Shimane 693, Japan.

Received for publication 26 April 1988 and in revised form 19 October 1988.

1. Abbreviations used in this paper: PE, phycoerythrin; PFC, plaqueforming cell; SAC, Staphylococcus aureus Cowan I.

J. Clin. Invest.

(c) The American Society for Clinical Investigation, Inc.

0021-9738/89/03/0937/08 $\$ 2.00$

Volume 83, March 1989, 937-944 creased numbers of B cells expressing unique activated B cell antigens, $\mathrm{Ba}$ antigens, on the surface are detected in the blood of SLE patients (1). Nonetheless, it is difficult to demonstrate that B cells of SLE patients excessively respond to in vitro stimuli in culture. Indeed, when SLE peripheral blood B cells are stimulated with B cell mitogens or exogenous antigens, they have rather markedly depressed in vitro responses to these stimuli (9-14). Therefore, there has not yet been convincing evidence that $B$ cells in patients with SLE may be endogenously hyperactive, so that such intrinsic B cell defect could bring about B cell hyperfunction.

Peripheral blood B cells contain B cells at various stages of activation. We have recently found that in normal humans, peripheral blood B cells sedimenting in a high density fraction on a Percoll density gradient consist of "genuine" small resting B cells and Percoll-separated low density B cells are of "partially" or "fully" activated large B cells (15). The small resting B cells (with high density) are stimulated by Staphylococcus aureus Cowan I (SAC) to proliferate vigorously without subsequent differentiation into Ig-secreting cells, while the latter B cells (with low density) can differentiate directly into Ig-secreting cells without the need for proliferation in response to $\mathrm{T}$ cell-derived soluble factors and/or SAC (15). Of interest is that some of $B$ cells with high density are moved to less density fractions after stimulation with SAC; the B cells shifting toward the low density fraction can differentiate into Ig-secreting cells in response to $\mathrm{T}$ cell factors and/or SAC (15). These data could be interpreted as indicating that "genuine" resting B cells and "partially" or "fully" activated B cells in the peripheral blood, at least in part, belong to the same cell lineage.

It is thus possible to evaluate excessive response of SLE B cells to in vitro stimuli in culture by utilizing this system. In this study, we have studied the ability of isolated "genuine" resting B cells from patients with SLE to respond to SAC. In particular, we have asked two questions: are the resting $B$ cells from patients with SLE more responsive than normal B cells to in vitro signals in culture? and does the excessive response of the $B$ cells arise from the preferential stimulation of specific $B$ cell subsets? We have found that the small resting $B$ cells of SLE patients proliferate in vitro at a significantly higher rate than normal B cells when exposed to SAC. In addition, stimulated SLE B cells that had been moved to low density fraction differentiated greater in presence of $T$ cell factors than controls. Moreover, the ability of the resting SLE B cells to respond to SAC was virtually identical among Leu $1^{+} B$ cells and Leu $1^{-} B$ cells. The results argue for a heightened excitability of the SLE B cell subsets including Leu $1^{+}$and Leu $1^{-}$B cells to triggering stimuli as a dominant factor in the etiology of the disease.

\section{Methods}

Patients. The 22 patients studied met the 1982 revised criteria for the classification of SLE by the American Rheumatism Association (16). 
Their mean age $( \pm \mathrm{SD})$ was $34.8 \pm 8.5 \mathrm{yr}$ (range 17-51), and all were female. Clinical activity was assessed at the time of blood drawing on the basis of clinical and laboratory findings (fever, active arthralgia, active rash, oral ulcers or alopecia, elevated erythrocyte sedimentation rate $[>30 \mathrm{~mm} / \mathrm{h}]$, leukopenia $[<4,000 / \mu \mathrm{l}]$, hypoalbuminemia $[<3.5$ $\mathrm{g} / \mathrm{dl}$ ], hypocomplementemia [ $\mathrm{CH}_{50}<20 \mathrm{U} / \mathrm{ml}$ ], positive LE-cell preparation) (17). Patients were categorized as active if they had three or four criteria of activity. The very active patients had at least five of the above criteria of activity. All the patients with active SLE, and those with very active disease also had high titers of antibodies to native DNA. If patients lacked symptoms and detectable signs of the activity, they were included in the inactive group. The 4,6 , and 26 patients had very active, active, and inactive disease, respectively. The six patients who were studied twice and the four patients studied three times, as described above, were assessed regarding disease activity category at each evaluation.

At the time of study, the four patients were receiving no treatment, and 18,8 , and 2 patients were receiving low doses (prednisolone, $2.5-10 \mathrm{mg} / \mathrm{d}$ ), intermediate doses (prednisolone, $12.5-30 \mathrm{mg} / \mathrm{d}$ ) and high doses (prednisolone, $\geq 40 \mathrm{mg} / \mathrm{d}$ ) of corticosteroids. The four patients were being treated with cytotoxic drugs (cyclophosphamide) together with prednisolone.

25 healthy blood donor ( 20 women and 5 men) served as control subjects. Their mean age $( \pm \mathrm{SD})$ was $32.9 \pm 7.5 \mathrm{yr}$.

Cell separations. Peripheral blood mononuclear cells were separated into $T$ cells and non- $T$ cells by means of a sheep red blood cell-rosette technique. B cells were obtained by further depletion of $T$ cells remaining in the non- $T$ cell fraction by complement-mediated cell lysis with OKT3 MAb. This was followed with depletion of monocytes by removal of cells adhering to petri dishes and by complementmediated cell lysis with OKM1 MAb (both from Ortho Pharmaceutical Corp., Raritan, NJ). All these purification procedures were repeated twice and have been described in detail elsewhere $(18,19)$.

The resultant $B$ cell population contained $\geq 90 \%$ cells reactive with anti-Leu $16 \mathrm{MAb}$, no cells reactive with anti-Leu $4 \mathrm{MAb}$ (both from Becton Dickinson, Monoclonal Center, Inc., Mountain View, CA), $<0.2 \%$ cells reactive with OKM5 MAb (Ortho Pharmaceutical), and $<1 \%$ cells reactive with OKNK MAb (Ortho Pharmaceutical). Moreover, the B cells obtained did not respond at all to phytohemagglutinin (Wellcome Research Laboratories, Wellcome Reagent Ltd., Beckenham, England) and concanavalin A (Pharmacia Fine Chemicals, Div. of Pharmacia Biotechnology International AB, Uppsala, Sweden) at their optimal concentrations (18).

Density gradient separation of $B$ cells. B cells were further separated by centrifugation on discontinuous Percoll density gradients as previously described $(15,20,21)$. Briefly, $5 \times 10^{6}-15 \times 10^{6} \mathrm{~B}$ cells, suspended in $2.5 \mathrm{ml}$ of $30 \%$ Percoll (Pharmacia Fine Chemicals) were layered onto the gradients ranging from 45 to $60 \%$ Percoll in 5\% increments of $2.5 \mathrm{ml}$ in $15-\mathrm{ml}$ centrifuge tubes (Iwaki Glass, Tokyo, Japan). The gradients were centrifuged at $3,000 \mathrm{~g}$ for $5 \mathrm{~min}$ at $4^{\circ} \mathrm{C}$. Cells at each interface were removed with a pasteur pipette. The layer between $\mathbf{4 5}$ and $50 \%$ Percoll is the low density fraction; between 50 and $55 \%$, the intermediate density fraction; and between 55 and $60 \%$, the high density fraction.

Isolation of Leu $1^{+}$and Leu $1^{-}$high density B cells. A panning technique was used to fractionate the Percoll-separated high density $B$ cells into Leu $1^{+}$and Leu $1^{-}$subsets (22). In this technique, 2 to $5 \times 10^{6}$ high density B cells were incubated for $60 \mathrm{~min}$ at $4^{\circ} \mathrm{C}$ with $100 \mu \mathrm{l}$ of anti-Leu 1 MAb (Becton Dickinson). Thereafter, the cells were incubated at $4^{\circ} \mathrm{C}$ for $90 \mathrm{~min}$ in plastic petri-dishes $(35 \times 10 \mathrm{~mm}$; Nunc, Roskilde, Denmark) which had been previously coated with affinitypurified rabbit anti-mouse IgG (Tago, Inc., Burlingame, CA; 10 $\mu \mathrm{g} / \mathrm{ml}$ ). The unbound cells (Leu $1^{-}$B cells) were collected; the dishes were then gently washed five times with culture medium, RPMI 1640 (Flow Laboratories Inc., McLean, VA) containing 10\% heat-inactivated fetal bovine serum (Flow Laboratories, Inc.), and bound cells (Leu $1^{+}$B cells) were recovered by vigorous pipetting. Less than $5 \%$ of the unbound cells were Leu $1^{+}$, and at least $80 \%$ of the bound cells were
Leu $\mathrm{1}^{+}$, on the basis of analysis by dual immunofluorescence staining using FITC-conjugated SL-1 MAb (Ortho Diagnostic Systems Inc., Tokyo, Japan), which can recognize a distinct epitope on the CD5 antigen from one recognized by anti-Leu $1 \mathrm{MAb}$, and phycoerythrin (PE)-conjugated anti-B1 MAb (Coulter Diagnostics, Coulter Electronics, Inc., Hialeah, FL).

Assay for SAC-induced proliferative responses of $B$ cell subsets. 5 $\times 10^{4} \mathrm{~B}$ cells with high density were stimulated with an optimal concentration of SAC $(0.002 \% \mathrm{vol} / \mathrm{vol})$ for various periods of time. Triplicate cultures in 96-well round-bottomed microtiter plates (Costar Data Packaging Corp., Cambridge, MA) were performed in a total volume of $200 \mu \mathrm{l}$ and incubated at $37^{\circ} \mathrm{C}$ in a humidified atmosphere of $5 \%$ $\mathrm{CO}_{2} / 95 \%$ air. Proliferative responses were measured by the incorporation of [methyl- ${ }^{3} \mathrm{H}$ ]thymidine $(2 \mathrm{Ci} / \mathrm{mmol}$; Amersham Corp., Arlington Heights, IL) over the last $20 \mathrm{~h}$ of the culture $(15,18)$.

Cell staining. Cell staining with MAb and data analysis were performed as previously described, with certain modifications (15). Cells were incubated with aggregated human IgG (Sigma Chemical Co., St. Louis, MO) for $45 \mathrm{~min}$ at $37^{\circ} \mathrm{C}$ (to prevent $\mathrm{Fc}$ fragment binding), washed, and allowed to react with optimal concentrations of mouse MAb, OKT9 (MAb to transferrin receptors; Ortho Pharmaceutical), anti-Tac and anti-B1. FITC-conjugated $F\left(a b^{\prime}\right)_{2}$ fragment of affinity-purified goat anti-mouse IgG (Tago, Inc.) was then used as a developing antibody. Cells were also directly stained with FITC-conjugated $\mathrm{F}\left(\mathrm{ab}^{\prime}\right)_{2}$ fragment of goat anti-human IgM, IgD, and IgG+IgA+IgM obtained from Cappel Laboratories, Cochranville, PA. Two-color immunofluorescence analysis was also carried out by cells stained with FITC-conjugated anti-Leu 1, or OKT3 MAb and PE-conjugated anti-Leu 16 MAb (22-25). Stained cells were analyzed by flow microfluorometry using a FACStar (Becton-Dickinson FACS System) or an Ortho Spectrum III (Ortho Diagnostic Systems, Inc.)

\section{Results}

Cell surface characteristics of high density $B$ cells in patients with SLE. In contrast to Percoll-separated high density B cells in normal subjects, almost all of which consist of "genuine" small resting B cells (15), high density B cells from patients with very active SLE, although composed of small $\operatorname{IgM}^{+} \operatorname{IgD}^{+}$ lymphocytes, were $2 \% \mathrm{Tac}^{+}$and $5 \%$ transferrin receptor ${ }^{+}$ (Table I). The Tac antigen and the transferrin receptor expression are generally accepted as reflections of lymphocyte activation (26). Moreover, these cells proliferated spontaneously and responded most to partially purified $T$ cell-derived soluble factors (Table I). The characterization of $\mathrm{T}$ cell factors used has been described in detail elsewhere (15). Cell cycle analysis (27, 28 ) of the B cells was shown that $\sim 10 \%$ of the cells are located in $S+G_{2}+M$ phase (Table I). When inactive patients lacking symptoms and detectable signs of activity were studied, their high density $\mathrm{B}$ cells composed of small $\mathrm{IgM}^{+} \mathrm{IgD}^{+}, \mathrm{Tac}^{-}$and transferrin receptor ${ }^{-}$cells, neither proliferated spontaneously, nor responded to $\mathrm{T}$ cell factors at all (Table $\mathrm{I}$ ). In addition, more than $99 \%$ of the cells had accumulated in' $G_{0} / G_{1}$ phase of cell cycle (Table I). The high density B cells from patients with active SLE were situated between the two (Table I). The data indicate that the "genuine" resting B cells can be obtained by collecting the high density small B cells only from patients with inactive SLE. Therefore, we investigated only lymphocytes obtained from SLE patients lacking any symptoms and detectable signs of activity in the present study.

Cell distribution of SLE B lymphocytes in each gradient fraction. Purified B cells from patients with inactive SLE were fractionated on Percoll discontinuous density gradients. Fig. 1 shows the percent cell distribution of B cells from individual patients in each gradient fraction. SLE patients had increased 
Table I. Characteristics of High Density B Cells from Patients with SLE at Various Disease Activity*

\begin{tabular}{|c|c|c|c|c|c|c|c|c|c|}
\hline \multirow[b]{3}{*}{ Source of high density B cells } & \multicolumn{4}{|c|}{ Surface markers } & \multirow{3}{*}{$\begin{array}{c}\text { Surface } \\
\operatorname{IgM}^{+} D^{-} / \mathrm{IgM}^{+} D^{+}\end{array}$} & \multirow{3}{*}{$\begin{array}{l}\text { Spontaneous } \\
\text { proliferation }^{\ddagger}\end{array}$} & \multirow{3}{*}{$\begin{array}{l}\text { Proliferation } \\
\text { in response } \\
\text { to } T \text { cell } \\
\text { factors }\end{array}$} & \multirow{2}{*}{\multicolumn{2}{|c|}{ Cell cycle analysis" }} \\
\hline & \multirow{2}{*}{$\begin{array}{l}\text { Surface } \\
\text { Ig }^{+}\end{array}$} & \multirow[b]{2}{*}{$\mathrm{B}^{+}{ }^{+}$} & \multirow[b]{2}{*}{$\mathrm{Tac}^{+}$} & \multirow{2}{*}{$\begin{array}{c}\text { Transferrin } \\
\text { receptor }^{+}\end{array}$} & & & & & \\
\hline & & & & & & & & $G_{0} / G_{1}$ & $\mathrm{~S}+\left(G_{2} / \mathrm{M}\right)$ \\
\hline & $\%$ & $\%$ & $\%$ & $\%$ & & $\Delta c p m \times 10^{-3}$ & $\times 10^{4}$ cells & $\%$ & $\%$ \\
\hline \multicolumn{10}{|l|}{ SLE patients (peripheral blood) } \\
\hline Very active $(3)^{* *}$ & $>90$ & $>90$ & $\underline{2.0^{\ddagger \ddagger}}$ & $\underline{5.0}$ & 0.005 & $\underline{2.4}$ & $\underline{1.8}$ & $>\underline{90}$ & $<\underline{10}$ \\
\hline Active (5) & $>90$ & $>90$ & $\overline{\mathrm{ND}}$ & $\underline{3.0}$ & 0.004 & $\underline{0.7}$ & $\underline{0.9}$ & $>\underline{95}$ & $<\underline{5}$ \\
\hline Inactive (10) & $>90$ & $>90$ & 0.5 & 0.7 & 0.005 & 0.2 & 0.3 & $>99$ & $<\overline{1}$ \\
\hline \multicolumn{10}{|l|}{ Normal controls (14) } \\
\hline (peripheral blood) & $>90$ & $>90$ & 0.3 & 0.5 & 0.003 & 0.2 & 0.3 & $>99$ & $<1$ \\
\hline \multicolumn{10}{|l|}{ Normal controls (3) } \\
\hline (SAC-activated cells) & $>90$ & $>90$ & $\underline{39.3}$ & $\underline{51.1}$ & 0.003 & $\underline{10.0}$ & ND & ND & ND \\
\hline
\end{tabular}

* Purified B cells were further fractionated on Percoll discontinuous density gradients, and cells sedimenting in the fraction of high density B cells (fraction between 55 and $60 \%$ Percoll) were analyzed for their characteristics. ${ }^{\ddagger}$ Spontaneous proliferation was measured by the incorporation of $\left[{ }^{3} \mathrm{H}\right]$ thymidine during the first $20 \mathrm{~h}$ of culture. ${ }^{8}$ Partially purified $\mathrm{T}$ cell-derived soluble factors $(15,18)$ and $\left[{ }^{3} \mathrm{H}\right]$ thymidine were added to cultures of B cells, and proliferative responses were measured by the incorporation of $\left[{ }^{3} \mathrm{H}\right]$ thymidine during the following $20 \mathrm{~h}$. " Cell cycle analysis was performed by using ethidium bromide staining $(15,28,29)$. ' $\Delta \mathrm{cpm}$ was calculated by subtracting background counts per minute (counts per minute of cultures containing medium alone) from counts per minute of cultures containing B cells with/without $T$ cell-derived soluble factors. ${ }^{* *}$ Numbers of subjects studied are represented in parentheses, and results expressed as the mean of the individual groups. ${ }^{\ddagger}\left({ }_{-}\right)$indicates significant difference by Student's $t$ test $(P<0.02)$ compared with the values observed in peripheral blood high density B cells of normal controls. ND, not done.

numbers of large $B$ cells sedimenting in the low density fraction (between $45 \%$ and $50 \%$ Percoll) and of those in further less density fraction (between $30 \%$ and $45 \%$ Percoll). In contrast, the number of small $B$ cells sedimenting in the high density fraction (between $55 \%$ and $60 \%$ Percoll) was significantly decreased. This is consistent with in vivo activation of B cells in

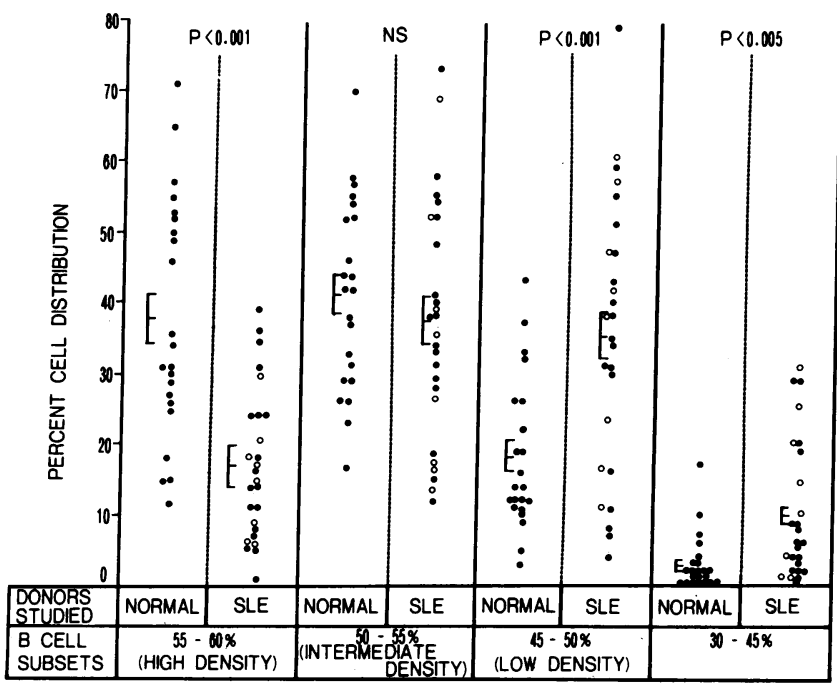

Figure 1. B cell distribution on Percoll density gradient centrifugation in patients with inactive SLE. Each circle represents the relative cell number distribution (percent) of B lymphocytes in each gradient fraction of individual donors, and the lines show mean \pm SE. $\bullet$, patients with inactive SLE who were receiving either no treatment (4 cases) or low doses of corticosteroids (14 cases; prednisolone, 2.5-10 $\mathrm{mg} / \mathrm{d}$ ) at the time of study; $\circ$, those who were receiving either intermediate doses of corticosteroids ( 5 cases; prednisolone, 12.5-30 $\mathrm{mg} / \mathrm{d}$ ) or cyclophosphamide plus prednisolone ( 3 cases). NS, not significant. patients with SLE, regardless of disease activity, as has been previously reported (1-7).

$S A C$-induced proliferative response of SLE $B$ cells of the high density. We have previously reported that SAC-activation pushes only genuine resting B cells with high density to proliferate vigorously (15). To determine if SLE resting B cells are more hyperactive in nature than normal resting B cells, we selected the patients with entirely inactive SLE for the present study. Moreover, since it has been well known that treatment, particularly with cytotoxic agents or corticosteroids, could affect the lymphocyte functions, only the 18 inactive patients who were receiving either no treatment or low doses of corticosteroid therapy (prednisolone, $2.5-10 \mathrm{mg} / \mathrm{d}$ ) (solid circles in Fig. 1) were studied to eliminate possible influence of therapy. Percoll-separated B cells of the high density from such selected patients were cultured with SAC for $3 \mathrm{~d}$ and measured their proliferative responses. As shown in Fig. 2, it is clear that the SAC-response is significantly higher in the B cells from SLE patients than in the B cells of normal subjects. Moreover, kinetic study demonstrated that although proliferation on day 1 of culture in both SLE and normal resting B cells were quite negligible, the significant proliferation is obtained after $2 \mathrm{~d}$ of culture in SLE resting B cells, while significant response appears $3 \mathrm{~d}$ after initiation of culture in normal resting $B$ cells (Fig. 2). The B cell hyperactivity by high density B cells obtained from the patients with SLE could occur independently of spontaneous B cell proliferation, because SLE high density B cells did not proliferate spontaneously regardless of the culture period (Fig. 2). In addition, the high density B cells from inactive SLE patients and normal controls did not respond to $T$ cell factors at all (Table I). The overall results indicate that SLE resting B cells exhibit accelerated and enhanced response when stimulated with SAC. In contrast, the high density B cells from patients with very active or active SLE which contained substantial numbers of activated cells (Table I) showed lesser 


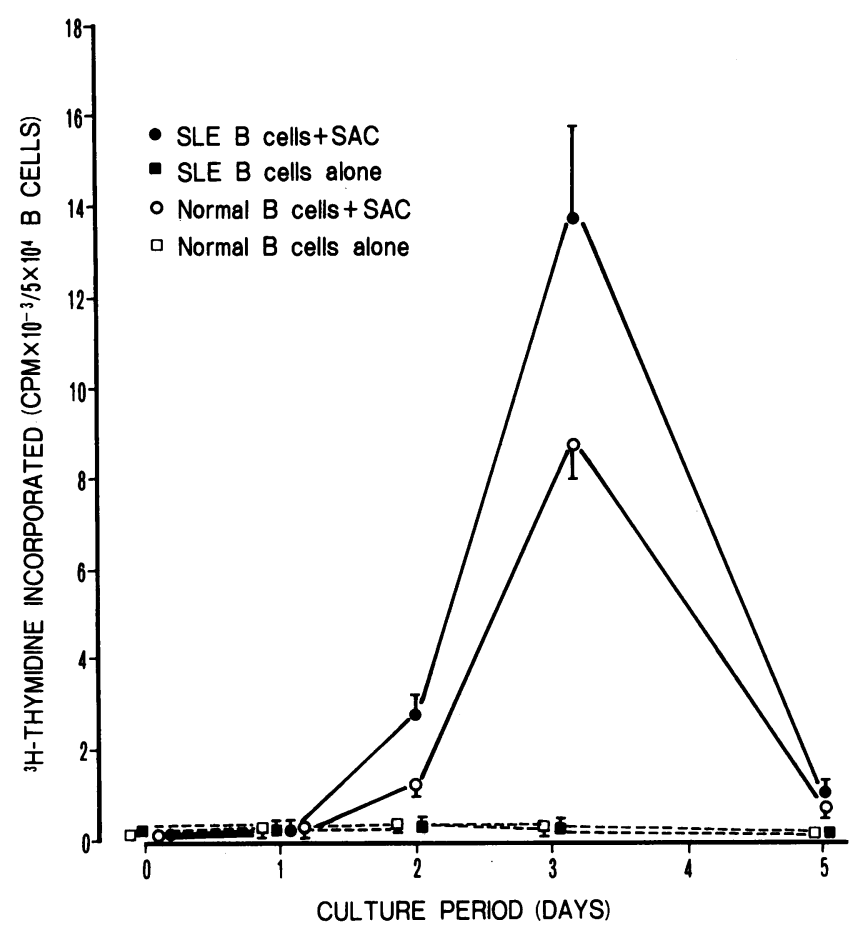

Figure 2. Proliferative responses of the high density B cells from patients with inactive SLE to SAC-stimulation. Percoll-fractionated high density B cells were obtained from 18 patients with entirely inactive SLE who were receiving no treatment or being treated with low doses of corticosteroids (prednisolone, $2.5-10 \mathrm{mg} / \mathrm{d}$ ), or from 21 normal controls. These B cells $\left(5 \times 10^{4}\right)$ were cultured for the indicated periods with or without SAC $(0.002 \% \mathrm{vol} / \mathrm{vol})$ and proliferative responses were measured by incorporation of $\left[{ }^{3} \mathrm{H}\right]$ thymidine during the last $20 \mathrm{~h}$ of culture. Data represent the mean counts per minute plus or minus SE.

responses to SAC compared with those of either inactive patients or normal controls (mean $\Delta \mathrm{cpm} \times 10^{-3} \pm \mathrm{SE}$ of SAC-induced proliferative response on day 3 for four patients with very active disease, 4.1 \pm 1.9 ; and for six active patients, $4.9 \pm 1.0)$

Reevaluation of $S A C$-induced B cell proliferative responses in the patients with inactive SLE. In the three specific patients with entirely inactive SLE, SAC-induced proliferative responses of their high density B cells in the peripheral blood were repeated 12-14 mo after the initial evaluation; their disease activity was not changed between the evaluations. As shown in Table II, the excessive B cell responsiveness in indi-

Table II. Reevaluation of SAC-induced B Cell Proliferative Response in the Three Patients with Inactive SLE

\begin{tabular}{cccc}
\hline Patient & $\begin{array}{c}\text { Months after } \\
\text { initial evaluation }\end{array}$ & $\begin{array}{c}\text { Dose of } \\
\text { prednisolone }\end{array}$ & $\begin{array}{c}\text { SAC-induced proliferation } \\
\text { by high density B cells }\end{array}$ \\
\hline \multirow{3}{*}{1} & & $m g / d$ & $\Delta c p m \times 10^{-3} / 5 \times 10^{4}$ B cells \\
& - & 5 & 12.6 \\
2 & 12 & 0 & 10.0 \\
& 13 & 7.5 & 23.3 \\
3 & 13 & 10 & 23.4 \\
& 14 & 7.5 & 9.1 \\
& 14 & 0 & 11.8
\end{tabular}

vidual patients appeared to be fairly stable over the periods. The results strongly suggest that the B cell hyperactivity observed could be due to intrinsic characteristics of SLE lymphocytes and thus contribute to the disease.

Frequency of Leu $1^{+} B$ cells in SLE peripheral blood. In mice, $\mathrm{Ly}-\mathrm{I}^{+} \mathrm{B}$ cells can be distinguished from other conventional B cells phenotypically, physiologically, and functionally. Indeed, some groups suggest that these cells may constitute a lineage distinct from $\mathrm{Ly}-\mathrm{1}^{-}$B cells (29). One of the most distinctive features of the $\mathrm{Ly}-\mathrm{I}^{+} \mathrm{B}$ cells is the secretion of large amounts of autoantibodies together with poor response to foreign antigens, resulting in a biased response favoring autoantibody specificities (30). Since the human homology of Ly-1, known as Leu 1 is also found on a fraction of B cells (31), we have next examined whether the Leu $1^{+} B$ cell subset is expanded in the peripheral blood of SLE patients and thus responsible for the excessive responsiveness to in vitro stimulus in culture by the SLE resting B cells. The first set of experiments was designed to identify and quantitate Leu $1^{+} B$ cells in control subjects and the patients with SLE. Peripheral blood mononuclear cells were treated with PE-conjugated anti-Leu 16 together with FITC-conjugated anti-Leu 1 and analyzed by a flow cytofluorometric cell sorter for the presence of B cells bearing Leu 1 marker. Because surface labeling with anti-Leu 1 does not delineate discrete subpopulation of $B$ cells, comparative staining with a FITC-labeled IgG2a isotype matched control was required (Fig. 3). To determine the percentage of

\section{1) Unfractionated MNC}
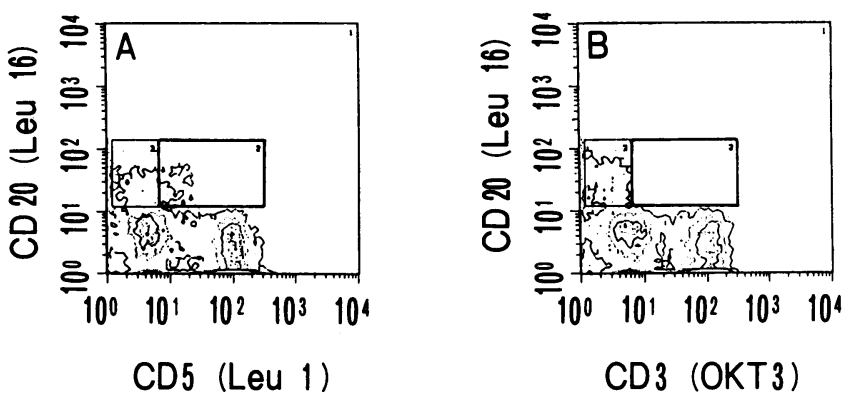

\section{2) High Density MNC}
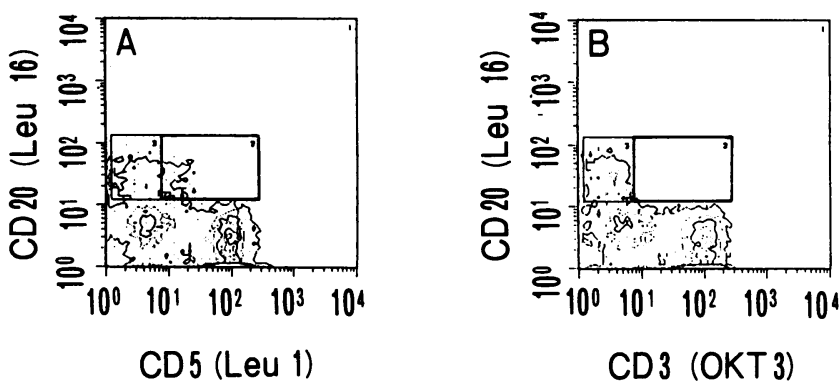

Figure 3. Two-color immunofluorescence of peripheral blood mononuclear cells from a healthy control stained with PE-conjugated antiLeu $16(\mathrm{CD} 20)$ and FITC-conjugated anti-Leu 1 (CD5) $(A)$ or FITClabeled IgG2a control mAb (OKT3) $(B)$. Boxed area represents area of integration used to calculate percent Leu $1^{+}$B lymphocytes. Percent number of cells in boxed area of $A$ is subtracted from the percent number of cells in boxed area of $B$ to determine the percent of Leu $1^{+}$B lymphocytes. 
Table III. Leu $1^{+}$B Cells in the Individual B Cell Subsets in Patients with SLE

\begin{tabular}{llrrr}
\hline & \multicolumn{4}{c}{ B cell subsets } \\
\cline { 2 - 5 } & Unfractionated & High density & \multicolumn{3}{c}{$\begin{array}{c}\text { Intermediate } \\
\text { density }\end{array}$} & Low density \\
& & \multicolumn{4}{c}{ percent $\pm S E$} \\
Normal controls (8)* & $23.2 \pm 3.7$ & $27.8 \pm 2.8$ & $20.3 \pm 2.3$ & $13.8 \pm 3.0$ \\
Patients with SLE (8) & $\underline{11.1 \pm 4.1^{\ddagger}}$ & $18.6 \pm 6.3$ & $\underline{9.5 \pm 3.5}$ & $\underline{5.8 \pm 1.7}$ \\
& & & & \\
\hline
\end{tabular}

* Numbers of subjects studied are represented in parentheses.

${ }^{\ddagger}\left(-\right.$ ) indicates significant decrease in the percentage of Leu $1^{+} \mathbf{B}$ cells by Student's $t$ test $(P<0.05)$ when compared to that in the corresponding B cell subsets of normal controls.

Leu $1^{+} B$ cells, the percent of isotype control (OKT3)-stained Leu $16^{+}$lymphocytes within the boxed fluorescence gate (Fig. 3 ) is subtracted from the percent of anti-Leu 1-stained Leu $16^{+}$ lymphocytes in the same fluorescence gate (Fig. 3). Other control included dual immunofluorescence labeling with OKT3 and anti-Leu 1. The percentage of lymphocytes expressing Leu 16 and OKT 3 was never noted above $0.5 \%$. The percentage of cells expressing Leu 1 and not OKT3 was always equal to, or slightly greater than the percentage of circulating Leu $1^{+} \mathrm{B}$ cells from any given individual (data not shown). By this procedure, the percentage of Leu $1^{+}$B lymphocytes in the peripheral blood mononuclear cells, unfractionated or Percoll-fractionated of normal controls and the SLE patients was measured. As shown in Table III, the SLE patients did not have significantly greater numbers of Leu $1^{+} B$ cells in the peripheral blood $B$ cells than did the control group. Rather, among the individual B cell subsets, less frequency of Leu $1^{+}$B cells was observed in patients with SLE compared with that in normal subjects (Table III).

Proliferation of Leu $1^{+}$and Leu $1^{-}$SLE B cells with high density in response to $S A C$. We next asked if the Leu $1^{+} B$ cells from the patients with SLE preferentially proliferate in response to SAC-stimulation. To this end, SLE resting high density $B$ cells were further divided into Leu $1^{+} B$ cells and Leu $1^{-}$ $B$ cells by means of panning technique using anti-Leu $1 \mathrm{MAb}$. The Leu $1^{+}$and Leu $1^{-}$resting B cells were then cultured for 3 $\mathrm{d}$ with or without SAC, and assayed for their proliferative responses. As shown in Fig. 4, proliferative responses to SAC were predominantly made by Leu $1^{+} B$ cells in normal subjects $(P<0.005)$. However, proliferation after SAC-stimulation was approximately the same among Leu $1^{+}$and Leu $1^{-} B$ cells in the patients with SLE. Moreover, both the B cell subsets from the patients with SLE stimulated with SAC, incorporated a larger amount of $\left[{ }^{3} \mathrm{H}\right]$ thymidine than the corresponding subsets from normal controls $(P<0.005)$. These results clearly demonstrated that SLE resting B cells are hyperactive to activation signals: the $B$ cell hyperactivity that developed in patients with SLE results from a proportionate excessive responsiveness of the individual B cell subsets, Leu $1^{+}$and Leu $1^{-}$B cells.

Differentiation of stimulated SLE B cells into Ig-secreting cells. We have previously shown in normal humans that although B cells with high density preferentially proliferate in response to SAC with subsequent poor differentiation into Igsecreting cells, some of the B cells shifting toward a low density fraction after $3 \mathrm{~d}$ stimulation can differentiate in response to $\mathrm{T}$

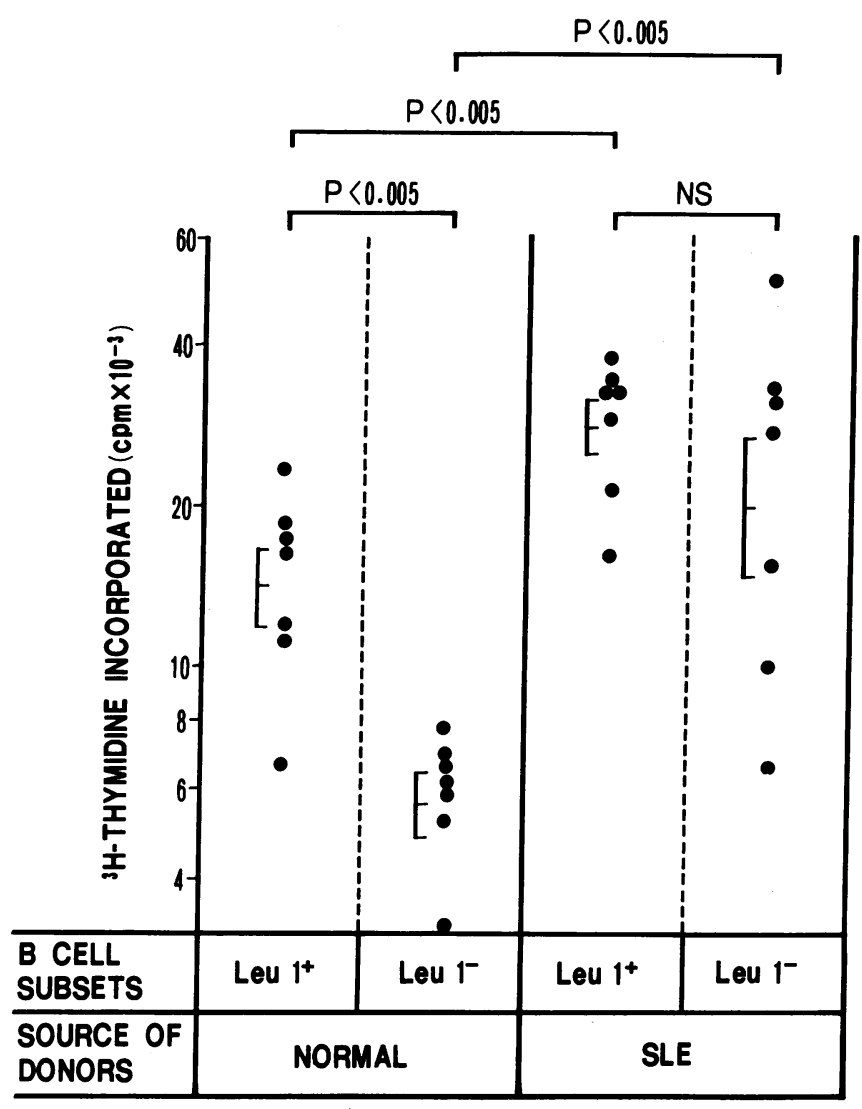

Figure 4. Proliferative responses of Leu $1^{+}$and Leu $1^{-}$B lymphocytes from patients with inactive SLE and normal controls. The high density $B$ cells were further fractionated into Leu $1^{+}$and Leu $1^{-}$subsets by means of panning technique. $5 \times 10^{4} \mathrm{~B}$ cell subsets were incubated for $3 \mathrm{~d}$ with SAC and proliferative responses were measured by incorporation of $\left[{ }^{3} \mathrm{H}\right]$ thymidine during the last $20 \mathrm{~h}$ of culture. Each circle represents the proliferative responses of Leu $1^{+}$or Leu $1^{-}$ high density $B$ cells from individual donors, and the lines show mean $\pm \mathrm{SE}$. Incorporation of $\left[{ }^{3} \mathrm{H}\right]$ thymidine by either subset of the cells alone cultured for $3 \mathrm{~d}$, was less than $100 \mathrm{cpm}$ in both the SLE patients and normal controls.

cell factors (15). Since SLE resting B cells with high density exhibited an enhanced proliferation in response to SAC, patients with SLE would have higher numbers of $B$ cells being moved to the low density fraction after stimulation of high density B cells for $3 \mathrm{~d}$ with SAC than normal subjects. To address this point, only high density resting $B$ cells were recovered by centrifugation of Percoll density gradients from freshly isolated peripheral blood B cells of SLE patients, stimulated for $3 \mathrm{~d}$ with SAC, and refractionated on Percoll density gradients. Thereafter, the refractionated $B$ cells were further incubated for $5 \mathrm{~d}$ with $\mathrm{T}$ cell factors, and measured for their IgG+IgA+IgM PFC responses. PFC were detected in a reverse hemolytic PFC assay according to the method of Gronowicz et al. (32).

As shown in Fig. 5, patients with inactive SLE had many more cells shifting toward the fraction of low density B cells after stimulation of high density B cells with SAC than normal subjects. Moreover, stimulated SLE B cells in a low density fraction that had been induced from B cells in a high density fraction produced significantly higher numbers of Ig-secreting cells when exposed to $\mathrm{T}$ cell factors than controls (Fig. 5). 


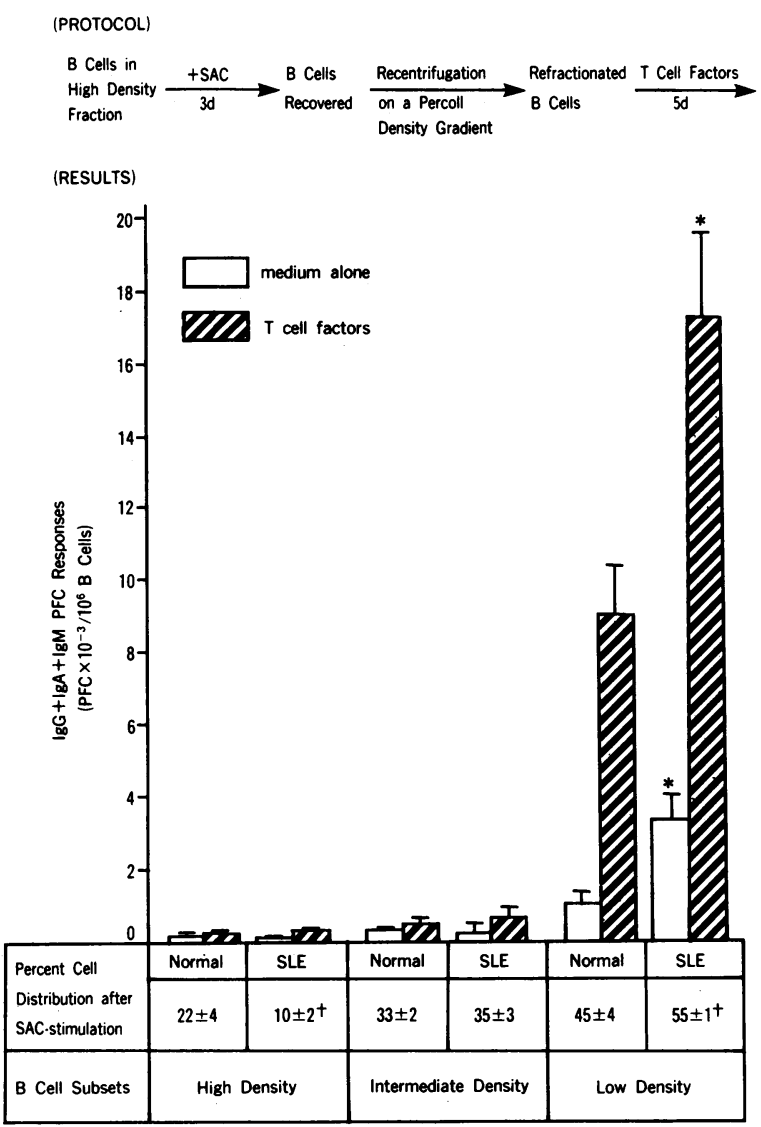

Figure 5. SAC-induced IgG+IgA+IgM-PFC responses by Percollfractionated $B$ cells after preincubation of $B$ cells sedimenting in a high density fraction on Percoll for $3 \mathrm{~d}$ with SAC. B cells that had sedimented in a high density fraction on the Percoll gradients were stimulated for $3 \mathrm{~d}$ with SAC $(0.002 \% \mathrm{vol} / \mathrm{vol})$ and refractionated by the Percoll density gradients. Refractionated cells were then tested on their differentiation responses by $\mathrm{T}$ cell-derived soluble factors $(40 \%$ $\mathrm{vol} / \mathrm{vol})$. The results are shown as the mean PFC responses plus SE of four normal donors and four SLE patients. *PFC responses by the $B$ cells with low density was significantly higher in patients with SLE compared with those in normal controls $(P<0.05)$. ${ }^{\dagger}$ Numbers of the $B$ cell subsets in patients with SLE were significantly different from those of the corresponding subsets in normal controls $(P<0.05)$.

\section{Discussion}

B cell hyperactivity is fundamental to SLE. As a result, the proximate cause of its problems relates, in large measure, to the B cell hyperactivity. The reason for the development of the B cell hyperactivity has not yet been established; SLE B cells may be by themselves endogenously hyperactive. However, the basis for the B cell hyperactivity is difficult to study in vitro (9-14).

Studies of our own (1) and those of others (3-7) have shown that most patients with SLE have increased numbers of activated B cells in their peripheral blood. These B cells appeared to have been already activated in vivo. Since activated B cells can, in general, cease to respond to additional in vitro stimuli (33-35), it is possible that in vitro additional stimuli would not necessarily drive the in vivo activated $B$ cells in SLE. Therefore, the in vitro response of real resting B cells in the peripheral blood of SLE patients must be compared to the response of those from normal subjects.
Although almost all B cells in the peripheral blood of normal subjects that have sedimented in fraction of a high density on a Percoll density gradient consist of "genuine" small resting B cells, it has to be claimed that B cells sedimenting in a high density fraction may always be of the resting B cells. Indeed, Nakagawa et al. (26) have recently reported that when SACactivated $B$ cells are separated according to their densities, high density small B cells have activation antigens such as transferrin receptor and 4F2 antigens and exhibit vigorous proliferation in response to high molecular weight $B$ cell growth factor. We also found that when the normal peripheral blood B cells are first stimulated for $3 \mathrm{~d}$ with SAC and fractionated on Percoll gradients, the high density $B$ cells are of small lymphocytes, have both IgM and IgD on the surfaces, do express activation antigens, and do incorporate a large amount of $\left[{ }^{3} \mathrm{H}\right]$ thymidine spontaneously (Table I). Moreover, the present study revealed that similar cell surface antigens and similar functional characteristics are detected in small numbers of Percoll-separated high density B cells in the peripheral blood of patients with very active SLE as well as those with active SLE. The recent data obtained from Tanaka et al. (36) who have reported that B cell-B cell interactions are sufficient for high density B cells to become low density PFC in patients with active SLE also support our finding that peripheral blood B cells sedimenting in a high density fraction contain substantial numbers of small B cells that have been already activated in vivo in patients with active SLE. In contrast, the high density $B$ cells in the peripheral blood from inactive SLE patients neither proliferate spontaneously nor respond to $T$ cell factors; they never express activation antigens. This is true regardless of individual patients with inactive SLE. The results suggest that circulating high density B cells of inactive SLE patients are located in a resting stage of cell cycle.

The responses of the resting $B$ cells from the patients with inactive SLE markedly differ from the responses of the normal resting $B$ cells and these differences are mainly quantitative rather than qualitative. The maximal response on day 3 is higher in the inactive SLE patients than normal subjects when exposed to SAC. Furthermore, the B cells of inactive SLE patients have evidence of the significant response as early as 2 d of culture, while the normal B cells develop the significant response after $3 \mathrm{~d}$ of culture. In addition, many more cells of Percoll-separated high density B cells in inactive SLE patients have been moved to less density fraction when exposed to SAC for $3 \mathrm{~d}$ than normal controls; there is an excessive differentiation by these $B$ cells that have been moved to less density fraction in response to standard in vitro lymphokine challenges. Thus, the resting B cells of patients with SLE once triggered by the activation signals, give abnormally excessive proliferation and differentiation which might be the basis of their autoimmune diseases. The data in the present study as well as in the previous study (37) closely parallel the B cell hyperactivity reported in some strains of lupus-prone mice (38-41).

The reason for the hyperactivity of the SLE resting B cells to the in vitro immunologic signals has not yet been elucidated in the present study. Several possibilities could be considered. The B cell may be intrinsically hyperactive. This could be a result of a primary B cell defect. Alternatively, since SAC-stimulated B cells produce lymphokines, and in turn, these lymphokines act on the $B$ cells to induce active proliferation and differentiation (42), the observed hyperactivity of the SLE B 
cells could be a results of excessive production of the lymphokines by SAC-stimulated SLE B cells. The abnormalities may also reside at the level of regulatory genes that control cell responsiveness after reception of a signal (41), thereby SLE resting $B$ cells might have an intrinsic property of hyperresponsiveness to the B cell-derived lymphokines.

Since SAC induces rheumatoid factor production more efficiently than other B cell mitogens (43), SAC may preferentially stimulate autoantibody-producing $B$ cells. If autoantibody-producing $B$ cells may be more enriched in the peripheral blood of SLE patients than in normal controls, SAC-stimulation may preferentially bring about the excessive response in patients with SLE. $\mathrm{CD5}^{+} \mathrm{B}$ cells have been reported to be importantly associated with autoantibody production in mice as well as in humans $(24,25,29-31,44)$. Therefore, we have asked whether numbers of Leu $1^{+} B$ cells are increased in the circulating B cells of SLE patients. There was rather less frequency of circulating lymphocytes coexpressing both Leu 1 and Leu 16 antigens in the inactive SLE patients than in the normal controls. In addition, we found that not only Leu $1^{+} \mathbf{B}$ cells but also Leu $1^{-}$B cells of the SLE patients are more responsive than those of normal subjects when stimulated with SAC. The results suggest that preferential activation and expansion of Leu $1^{+}$B cells are not necessary to bring about clinically obvious autoimmune diseases in humans. These findings in human SLE are different from previous reports in the lupus-prone NZB/W, and BXSB mice $(29,30,44)$. The differences may represent the differences of the lymphocyte source examined; peripheral blood is analyzed in the present study, and spleen cells in the lupus mice. Alternatively, since the abnormalities in human SLE may or may not be found in murine models of SLE, this may be the latter case; the finding that both Leu $1^{+}$and Leu $1^{-}$B cell subsets are endogenously hyperactive in SLE may be interpreted as consistent with autoantibody production not being limited to the $\mathrm{CD5}^{+} \mathrm{B}$ cells, at least in human SLE. Further efforts to identify the source(s) and nature of the agents responsible for the B cell stimulation may shed important light on the cause of this systemic autoimmune disease and ultimately lead to fruitful therapy of patients with SLE.

\section{Acknowledgments}

We wish to thank Dr. T. Tsuchiya of Nihon University School of Medicine (Tokyo, Japan) and Dr. T. Uchiyama of Kyoto University School of Medicine (Kyoto, Japan) for providing SAC and anti-Tac MAb, respectively. We are indebted to Ms. H. Horii for help in preparing the manuscript.

This work was supported in part by a 1988-1989 grant in aid for scientific research, project 63480191 , from the Ministry of Education, Science, and Culture of Japan, by a 1988 research grant from the Autoimmune Disease Research Committee of Japan, Ministry of Welfare of Japan, and by a 1986/1987 research grant from the Tokyo Biochemical Research Foundation, Tokyo, Japan.

\section{References}

1. Sakane, T., N. Suzuki, S. Takada, Y. Ueda, Y. Murakawa, T. Tsuchida, Y. Yamauchi, and T. Kishimoto. 1988. B cell hyperactivity and its relation to distinct clinical features and the degree of disease activity in patients with systemic lupus erythematosus. Arthritis Rheum. 31:80-87.

2. Steinberg, A. D., J. S. Smolen, T. Sakane, S. Kumagai, C. Mori- moto, T. M. Chused, I. Green, F. Hirata, K. A. Siminovitch, and R. T. Steinberg. 1982. Immune regulatory abnormalities in systemic lupus erythematosus. In Immune Mechanisms in Renal Disease. N. B. Cummings, A. F. Michael, and C. B. Wilson, editors. Plenum Publishing, New York. 529-548.

3. Glinski, W., M. E. Gershwin, D. R. Budman, and A. D. Steinberg. 1976. Study of lymphocyte subpopulations in normal humans and patients with systemic lupus erythematosus by fractionation of peripheral blood lymphocytes on a discontinuous Ficoll gradient. Clin. Exp. Immunol. 26:228-238.

4. Budman, D. R., E. B. Merchant, A. D. Steinberg, B. Doft, M. E. Gershwin, E. Lizzio, and J. P. Reeves. 1977. Increased spontaneous activity of antibody-forming cells in the peripheral blood of patients with active SLE. Arthritis Rheum. 20:829-833.

5. Ginsburg, W. W., F. D. Finkelman, and P. E. Lipsky. 1979. Circulating and pokeweed mitogen-induced immunoglobulin-secreting cells in systemic lupus erythematosus. Clin. Exp. Immunol. 35:76-88.

6. Blaese, R. M., J. Grayson, and A. D. Steinberg. 1980. Elevated immunoglobulin-secreting cells in the blood of patients with active systemic lupus erythematosus: correlation of laboratory and clinical assessment of disease activity. Am. J. Med. 69:345-350.

7. Fauci, A. S., and H. M. Moutsopoulos. 1981. Polyclonally triggered B cells in the peripheral blood and bone marrow of normal individuals and in patients with systemic lupus erythematosus and primary Sjögren syndrome. Arthritis Rheum. 24:577-584.

8. Kumagai, S., B. Sredni, S. House, A. D. Steinberg, and I. Green. 1982. Defective regulation of B lymphocyte colony formation in patients with systemic lupus erythematosus. J. Immunol. 128:258-262.

9. Jasin, H. E., and M. Ziff. 1975. Immunoglobulin synthesis by peripheral blood cells in systemic lupus erythematosus. Arthritis Rheum. 18:219-228.

10. Nies, K. M., and J. S. Louie. 1978. Impaired immunoglobulin synthesis by peripheral blood lymphocytes in systemic lupus erythematosus. Arthritis Rheum. 21:51-57.

11. Saiki, O., Y. Saeki, and S. Kishimoto. 1985. Spontaneous immunoglobulin A secretion and lack of mitogen-responsive B cells in systemic lupus erythematosus. J. Clin. Invest. 76:1865-1870.

12. Sawada, S., S. Amaki, M. Takei, M. Karasaki, and I. Amaki. 1985. Impaired B cell proliferation by Staphylococcus aureus Cowan I in patients with systemic lupus erythematosus. Arthritis Rheum. 28:1008-1015.

13. Delfraissy, J. F., P. Segond, P. Galanaud, C. Walland, P. Massias, and J. Dormon. 1980. Depressed primary in vitro antibody response in untreated systemic lupus erythematosus. $T$ helper cell defect and lack of defective suppressor cell function. J. Clin. Invest. 66:141148.

14. Morimoto, C., T. Abe, M. Hara, and M. Homma. 1977. In vitro TNP-specific antibody formation by peripheral lymphocytes from patients with systemic lupus erythematosus. Scand. J. Immunol. 6:575-579.

15. Suzuki, N., Y. Ueda, and T. Sakane. 1988. Differential mechanism for differentiation into immunoglobulin-secreting cells in human resting B lymphocyte subsets isolated on the basis of cell density. $J$. Clin. Invest. 81:261-269.

16. Tan, E. M., A. S. Cohen, J. F. Fries, A. T. Masi, D. J. McShane, N. F. Rothfield, J. G. Schaller, N. Talal, and R. J. Winchester. 1982. The 1982 revised criteria for the classification of systemic lupus erythematosus. Arthritis Rheum. 25:1271-1277.

17. Murakawa, Y., and T. Sakane. 1988. Deficient phytohemagglutinin-induced interleukin-2 activity in patients with inactive systemic lupus erythematosus is correctable by the addition of phorbol myristate acetate. Arthritis Rheum. 31:826-833.

18. Suzuki, N., T. Sakane, Y. Ueda, Y. Murakawa, and T. Tsunematsu. 1986. Implications for the role of cognate interactions in in vitro human B cell activation by Staphylococcus aureus Cowan I and pokeweed mitogen. J. Clin. Invest. 77:294-300.

19. Suzuki, N., and T. Sakane. 1988. Mechanism of T cell-derived 
helper factor production upon stimulation with pokeweed mitogen in humans. Clin. Exp. Immunol. 71:343-349.

20. Dagg, M. K., and D. Levitt. 1981. Human B-lymphocyte subpopulations. I. Differentiation of density-separated B lymphocytes. Clin. Immunol. Immunopathol. 21:39-49.

21. Kuritani, T., and M. D. Cooper. 1982. Human B cell differentiation. II. Pokeweed mitogen-responsive B cells belong to a surface immunoglobulin D-negative subpopulation. J. Exp. Med. 155:15611566.

22. Richard, Y., C. Leprince, B. Dugas, D. Treton, and P. Galanaud. 1987. Reactivity of Leu $1^{+}$tonsillar B cells to a high molecular weight B cell growth factor. J. Immunol. 139:1563-1567.

23. Kipps, T. J., and J. H. Vaughan. 1987. Genetic influence on the levels of circulating CD5 B lymphocytes. J. Immunol. 139:1060-1064.

24. Hardy, R. R., K. Hayakawa, M. Shimizu, K. Yamasaki, and T. Kishimoto. 1987. Rheumatoid factor secretion from human Leu $1^{+} \mathrm{B}$ cells. Science (Wash. DC). 236:81-83.

25. Casali, P., S. E. Burastero, M. Nakamura, G. Inghirami, and A. L. Notkins. 1987. Human lymphocytes making rheumatoid factor and antibody to ssDNA belong to Leu $1^{+}$B-cell subset. Science (Wash. DC). 236:77-81.

26. Nakagawa, T., N. Nakagawa, J. L. Ambrus, and A. S. Fauci. 1988. Differential effects of interleukin 2 vs B cell growth factor on human B cells. J. Immunol. 140:465-469.

27. Suzuki, N., T. Sakane, Y. Ueda, and T. Tsunematsu. 1986. Abnormal B cell function in patients with Behçet's disease. Arthritis Rheum. 29:212-219.

28. Vindeløv, L. L. 1977. Flow microfluorometric analysis of nuclear DNA in cells from solid tumors and cell suspension: a new method for rapid isolation and staining of nuclei. Virchows Arch. B. Cell Pathol. 24:227-242.

29. Hayakawa, K., R. R. Hardy, L. A. Herzenberg, and L. A. Herzenberg. 1985. Progenitors for Ly-1 B cells are distinct from progenitors for other B cells. J. Exp. Med. 161:1554-1568.

30. Hayakawa, K., R. R. Hardy, M. Honda, L. A. Herzenberg, A. D. Steinberg, and L. A. Herzenberg. 1984. Ly-1 B cells: functionally distinct lymphocytes that secrete IgM autoantibodies. Proc. Natl. Acad. Sci. USA. 81:2494-2498.

31. Ledbetter, L. A., R. L. Evans, M. Lipinski, C. CunninghamRundles, R. A. Good, and L. A. Herzenberg. 1981. Evolutionary con- servation of surface molecules that distinguish $\mathrm{T}$ lymphocyte helper/ inducer and cytotoxic/suppressor subpopulations in mouse and man. J. Exp. Med. 153:310-323.

32. Gronowicz, E., A. Coutinho, and S. F. Melchers. 1976. A plaque assay for all cells secreting $\mathrm{Ig}$ of a given type or class. Eur. $J$. Immunol. 6:588-590.

33. Fauci, A. S., A. D. Steinberg, B. F. Haynes, and G. Whalen 1978. Immunoregulatory aberrations in systemic lupus erythematosus. J. Immunol. 121:1473-1479.

34. Cohen, P. L., and M. Ziff. 1977. Abnormal polyclonal B cell activation in NZB/NZW $F_{1}$ mice. J. Immunol. 119:1534-1537.

35. Jacobs, M. E., A. D. Steinberg, J. K. Gordon, and N. Talal. 1972. Adjuvant effects of poly(I)-poly(C) in New Zealand mice. Arthritis Rheum. 15:201-207.

36. Tanaka, Y., F. Shirakawa, T. Ota, H. Suzuki, S. Eto, and U. Yamashita. 1988. Mechanism of spontaneous activation of B cells in patients with systemic lupus erythematosus: analysis with anti-class II antibody. J. Immunol. 140:761-767.

37. Tan, P., G. Pang, and J. D. Wilson. 1981. Immunoglobulin production in vitro by peripheral blood lymphocytes in systemic lupus erythematosus: helper $\mathrm{T}$ cell defect and B cell hyperreactivity. Clin. Exp. Immunol. 44:548-554.

38. Smith, H. R., and A. D. Steinberg. 1983. Autoimmunity: a perspective. Annu. Rev. Immunol. 1:175-210.

39. Theofilopoulos, A. N., and F. J. Dixon. 1985. Murine models of systemic lupus erythematosus. Adv. Immunol. 37:269-390.

40. Dixon, F. J. 1985. Murine lupus: a model for human autoimmunity. Arthritis Rheum. 28:1081-1088.

41. Prud'homme, G. J., R. S. Balderas, F. J. Dixon, and A. N. Theofilopoulos. 1983. B cell dependence on and response to accessory signals in murine lupus strains. J. Exp. Med. 157:1815-1827.

42. Muraguchi, A., H. Nishimoto, N. Kawamura, A. Hori, and T. Kishimoto. 1986. B cell-derived BCGF functions as autocrine growth factor(s) in normal and transformed B lymphocytes. J. Immunol. 137:179-186.

43. Levinson, A. I., L. Tar, C. Carafa, and M. Haidar. 1986. Staphylococcus aureus Cowan I. Potent stimulus of immunoglobulin $\mathbf{M}$ rheumatoid factor production. J. Clin. Invest. 78:612-617.

44. Hayakawa, K., R. R. Hardy, D. R. Parks, and L. A. Herzenberg. 1983. The "Ly-1 B" cell subpopulation in normal, immunodefective, and autoimmune mice. J. Exp. Med. 157:202-218. 